\title{
O COORDENADOR PEDAGÓGICO COMO ARTICULADOR DA FORMAÇÃO CONTINUADA DE PROFESSORES: O QUE PESQUISAS PUBLICADAS ENTRE 2010-2020 INDICAM
}

\section{The Pedagogical Coordinator as Articulator of Continuing Teacher Education: What Research Published between 2010-2020 Indicate}

\author{
Diessica Michelson Martins ${ }^{1}$ \\ Julia Stiebbe Callai ${ }^{2}$ \\ Vidica Bianchi ${ }^{3}$
}

\begin{abstract}
Resumo: A incessante busca por uma Educação de qualidade reflete-se na gama de pesquisas que estão disponibilizadas no meio virtual. Indo ao encontro disso, este estudo tem como objetivo apresentar uma revisão investigativa, do tipo Estado do Conhecimento, de produções científicas que abordam a formação continuada de professores com o coordenador pedagógico como mediador e articulador dessa ação nas escolas. O levantamento de dados foi realizado por meio do Portal de Periódicos da Coordenação de Aperfeiçoamento de Pessoal de Nível Superior e da Biblioteca Digital Brasileira de Teses e Dissertações por intermédio dos descritores: "formação continuada de professores" e "coordenador pedagógico". A natureza da pesquisa é qualitativa e segue os argumentos da Análise Textual Discursiva. Integraram-se no corpus da pesquisa 39 trabalhos que após serem selecionados foram organizados em categorias criadas indutivamente. Emergiram as seguintes categorizações: a) formação continuada; b) professores: formação e o ato reflexivo; c) formação, função e saberes do coordenador pedagógico; e d) relação coordenador-professor. Os resultados apontam para a percepção de que a formação in loco possui relevância para a constituição do ensino/práxis docente e eficácia da aprendizagem dos estudantes. Destarte, realizar esses momentos é papel do coordenador pedagógico, o qual precisa também de desenvolvimento profissional constante para estar apto a atuar como formador de professores nas escolas.
\end{abstract}

Palavras-chave: Formação docente. Coordenação pedagógica. Educação básica.

Abstract: The incessant search for quality education is reflected in the range of research that is available on the virtual environment. On this behalf, this study aimed to present an

\footnotetext{
${ }^{1}$ Mestranda em Educação nas Ciências pela Universidade Regional do Noroeste do Estado do Rio Grande do Sul (Unijuí). Bolsista Prosuc/Capes. Licenciada em Pedagogia pela Unijuí. Orcid:https://orcid.org/0000-0001-59475949. diessicammichelson@gmail.com.

${ }^{2}$ Mestranda em Educação nas Ciências pela Universidade Regional do Noroeste do Estado do Rio Grande do Sul (Unijuí). Bolsista Prosuc/Capes. Licenciada em Educação Física pela Unijuí. Orcid: https://orcid.org/0000-00017426-8681.juliecallai@hotmail.com.

${ }^{3}$ Doutora em Ecologia pela Universidade Federal do Rio Grande do Sul e Mestre em Educação nas Ciências pela Universidade Regional do Noroeste do Estado do Rio Grande do Sul (Unijuí). Pesquisadora em Controle Biológico, nos temas: biodiversidade, interações ecológicas, educação ambiental, formação de professores e estudos de currículo. Professora permanente dos Programas de Pós-Graduação em Educação nas Ciências e em Sistemas Ambientais e Sustentabilidade (Unijuí). Orcid: https://orcid.org/0000-0003-0277-019. vidica.bianchi@unijui.edu.br.
} 
investigative review, of the state of knowledge type, of scientific productions that address the continuing education of teachers with the pedagogical coordinator as mediator and articulator of this action in schools. This survey was carried out through the Portal of Periodicals of the Coordination for the Improvement of Higher Education Personnel and on the Brazilian Digital Library of Theses and Dissertations through the descriptors: "continuing education of teachers" and "pedagogical coordinator". The nature of the research is qualitative and it follows the arguments of Textual Discursive Analysis. 39 works were integrated in the research corpus, which, after being selected, were organized into categories created inductively. The following categories emerged: a) continuing education; b) teachers: training and the reflective act; c) training, function and knowledge of the pedagogical coordinator; and d) coordinator-teacher relationship. The results point to the perception that on-site training is relevant to the constitution of teaching / teaching praxis and the effectiveness of student learning. Thus, carrying out these moments is the role of the pedagogical coordinator, who also needs constant professional development to be able to act as a teacher educator in schools.

Keywords:Teacher education. Pedagogical coordination. Basic education.

\section{Introdução}

Para realçar a dimensão da temática aqui abordada-a formação continuada de professores articulada por coordenadores pedagógicos- é primordial entender o que é esta instituição chamada escola para, então, reconhecer a sua relevância na formação dos docentes, dos gestores pedagógicos e na organização das práticas pedagógicas. De acordo com Alarcão (2011), a escola é um espaço social do qual professores, alunos, funcionários, pais e representantes do poder municipal fazem parte e no qual se reconhecem como comunidade educativa.

Ao compreender a importância desse espaço social, seguimos em busca de evidenciar a pluralidade dos sujeitos que o rodeiam. Em primeiro lugar, a figura do coordenador pedagógico é assimilada com as atividades burocráticas e técnicas da escola. Essa ideia, no entanto, vem se modificando ao longo do tempo, juntamente com as transformações sociais e políticas do contexto educativo (DOMINGUES, 2014). Domingues (2014, p. 114) ressalta que "cabe à coordenação pedagógica coordenar as atividades de modo a promover uma consciência de si e do outro, ligadas por um projeto coletivo que estabeleça objetivos e metas comuns".

O coordenador pedagógico, nesse sentido, contribui para a qualificação docente ao criar estratégias que promovam melhorias nas ações pedagógicas cotidianas, que podem servir como base para repensar e reelaborar, conforme as necessidades de cada realidade educativa, as práticas didático-pedagógicas. Para que isso aconteça, contudo, esse profissional precisa ser competente e compreender sua função de formador de professores nas escolas. Tal tarefa exige o estabelecimento de relações com o coletivo para além da sala dos professores e corredores da escola, estendendo-se às próprias salas de aula e à sociedade.

O docente constitui e se apropria de muitos saberes no seu local de trabalho. Não obstante, é fundamental que, por intermédio do coordenador pedagógico - que carrega consigo a função de mediar momentos reflexivos e elaborar estratégias coletivas para promover processos de ensino e de aprendizagem qualificados -, sejam realizadas formações continuadas no ambiente escolar. Nóvoa (1995) corrobora com tal afirmação, pois, para ele, a formação não é um acúmulo de cursos ou técnicas, mas sim de trabalhos reflexivos sobre a prática, realizados de forma crítica com vistas a (re)construir a identidade pessoal. 
Tendo essas convicções em vista, o questionamento que fundamenta a finalidade desta revisão integrativa é: O que revelam as pesquisas, publicadas no período de 2010 a 2020 , que têm como foco a investigação sobre a formação continuada de docentes na escola, sob a mediação dos coordenadores pedagógicos? Diante disso, o propósito desta pesquisa é refletir sobre o que dizem estudos já publicados acerca da formação continuada de professores nas escolas e identificar/salientar a relevância que o coordenador pedagógico possui na realização dessa prática formativa, de aperfeiçoamento docente e qualificação do ensino/espaço escolar.

Para tanto, a partir de uma busca realizada no Portal de Periódicos da Coordenação de Aperfeiçoamento de Pessoal de Nível Superior (Capes) e na Biblioteca Digital Brasileira de Teses e Dissertações (BDTD) ${ }^{4}$ foi organizado um Estado do Conhecimento. Constitui-se, desse modo, um acervo bibliográfico analisado à luz da Análise Textual Discursiva (ATD). A seguir, detalhamos os procedimentos metodológicos adotados e apresentamos nas seções seguintes: os resultados, as considerações finais da pesquisa e as referências.

\title{
2 Procedimentos metodológicos
}

Esta pesquisa qualitativa está relacionada aos universos de significados que correspondem às relações entre fenômenos e processos explorados no seu decorrer. Para uma investigação científica ampla em quesitos de validade, é indispensável uma observação dos conceitos pré-existentes sobre o objeto de estudo, que possui caráter bibliográfico e que foi realizado a partir de um mapeamento de produções científicas no Portal de Periódicos da Capes e na BDTD. A busca foi realizada no dia 23 de fevereiro de 2021.

Para a realização de uma análise rigorosa, considerando a temática da pesquisa, foram adotados os princípios da ATD, que é "uma metodologia de análise de informações de natureza qualitativa com finalidade de produzir novas compreensões sobre fenômenos e discursos" (MORAES; GALIAZZI, 2020, p. 13). Esse método é pertinente para esta investigação não apenas porque visa a testar hipóteses, para então comprová-las ou refutá-las, mas por ter como foco a compreensão e a reconstrução de conhecimentos já existentes sobre o assunto investigado. Nesse sentido, o artigo enquadra-se ao que reconhecemos como Estado do Conhecimento, que diz respeito à construção de um estudo de caráter bibliográfico que tem como desafio

\begin{abstract}
[...] mapear e de discutir uma certa produção acadêmica em diferentes campos do conhecimento, tentando responder que aspectos e dimensões vêm sendo destacados e privilegiados em diferentes épocas e lugares, de que formas e em que condições têm sido produzidas certas dissertações de mestrado, teses de doutorado, publicações em periódicos e comunicações em anais de congressos e de seminários. Também são reconhecidas por realizarem uma metodologia de caráter inventariante e descritivo da produção acadêmica e científica sobre o tema que busca investigar, à luz de categorias e facetas que se caracterizam enquanto tais em cada trabalho e no conjunto deles, sob os quais o fenômeno passa a ser analisado (FERREIRA, 2002, p. 258).
\end{abstract}

Para concretizar o Estado do Conhecimento, os materiais selecionados foram organizados e analisados detalhadamente. Durante esse processo, o corpus foi investigado considerando as três fases da ATD: desmontagem dos textos e criação de unidades de sentido;

\footnotetext{
${ }^{4}$ A BDTD foi escolhida por possuir uma parceria com as instituições de ensino e pesquisa, e por oferecer à comunidade acadêmica o acesso a teses e dissertações nacionais e internacionais, embora possua maior ênfase na divulgação de pesquisas brasileiras.
} 
estabelecimento de relações e criação de categorias; captação do novo emergente e a comunicação por meio de metatextos (MORAES; GALIAZZI, 2020). A seleção e desmontagem dos textos é abordada a seguir. Assim, buscamos explicar como foi realizada a pesquisa, a leitura e a significação do corpus unitizado.

O portal de periódicos da Capes abrange uma variedade de pesquisas científicas nacionais e internacionais e é considerado uma das melhores bibliotecas virtuais, posto que contém em seu acervo mais de 45 mil títulos. Para a realização do mapeamento proposto, alguns processos foram considerados: 1) O portal de periódicos da Capes foi acessado por meio do acesso remoto via $\mathrm{CAFe}^{5}$; 2) Foi selecionado, em pesquisa avançada, o período de janeiro de 2010 até dezembro de 2020; 3)Foram utilizados os descritores: "formação continuada de professores" e "coordenador pedagógico".

\subsection{Passos da busca no periódico Capes:}

$1^{\circ}$ momento: Foi realizada uma busca com o uso do descritor "formação continuada de professores" e, como resultado, foram encontradas 2.214 pesquisas. Destas, apenas 1.519 foram revisadas por pares.

$2^{\mathrm{o}}$ momento: $\mathrm{O}$ mesmo processo de busca foi realizado, porém,utilizando o descritor “coordenador pedagógico". Nessa busca foram obtidos 498 resultados, sendo que, destes, 90 não foram revisados por pares.

$3^{\circ}$ momento: Com o intuito de realizar uma busca mais avançada e específica, utilizamos o booleano AND, para limitar os resultados e obter pesquisas mais próximas do objetivo deste estudo. Dessa maneira, foi feita uma busca com ambos os descritores, referente ao mesmo período de tempo. O resultado obtido foi de 119 estudos, dos quais apenas 77 foram revisados por pares.

Tabela 1 - Resultados das buscas das produções no Portal de Periódicos da Capes, no período de 2010-2020

\begin{tabular}{c|c|c}
\hline \multicolumn{2}{c}{ DESCRITORES } & \multicolumn{2}{c}{ TOTAL } & \multicolumn{1}{c}{ REVISADO POR PARES } \\
\hline Formação continuada de professores & 2.214 & 1.519 \\
Coordenador pedagógico & 498 & 408 \\
Formação continuada de professores AND coordenador pedagógico & 119 & 77 \\
\hline
\end{tabular}

Fonte: Dados da pesquisa (2021).

$4^{\circ}$ momento: Os 77 trabalhos selecionados, revisados por pares, foram analisados, observando-se o resumo, palavras-chave, considerações finais e referências. Com base nessas observações, apenas 4 artigos estão próximos ao tema deste estudo. Após a seleção de artigos, foi realizada a busca na BDTD. Nesse site, o mapeamento foi delimitado da mesma maneira que no Portal de Periódicos da Capes, considerando-se as mesmas etapas (4) e os mesmos descritores. Como resultado, obteve-se o que apresentamos na Tabela 2.

\footnotetext{
${ }^{5} \mathrm{O}$ acesso CAFe permite que os estudantes tenham acesso remoto ao conteúdo assinado pela sua instituição, o qual fica disponível no Portal de Periódicos da Capes em aba específica.
} 
Tabela 2 - Resultados das buscas das produções na Biblioteca Digital Brasileira de Teses e Dissertações, no período de 2010-2020

\begin{tabular}{c|c|c|c}
\hline DESCRITORES & \multicolumn{1}{c}{ DISSERTAÇÃo } & \multicolumn{1}{c}{ TESE } & \multicolumn{1}{c}{ TOTAL } \\
\hline Formação continuada de professores & 3.995 & 1.392 & 5.387 \\
Coordenador pedagógico & 1.630 & 513 & 2.143 \\
$\begin{array}{c}\text { Formação continuada de professores AND coordenador } \\
\text { pedagógico }\end{array}$ & 400 & 92 & 492 \\
\hline
\end{tabular}

Fonte: Dados da pesquisa (2021).

As 492 produções foram analisadas, levando em consideração o resumo, os objetivos, as palavras-chave, a introdução, as considerações finais, as referências utilizadas no decorrer das discussões e se eram pertinentes ou não a este estudo. Após a análise, foram selecionadas 33 dissertações e duas teses para serem analisadas à luz da ATD, por estarem alinhadas ao objetivo desta pesquisa.

As teses, dissertações e artigos que compõem o corpus da pesquisa foram organizados em quadros para análise, o que permitiu a identificação de quatro categorias, de acordo com o método indutivo. Essas categorias emergiram da seguinte maneira: em um primeiro momento, foram elencadas as ideias centrais de cada pesquisa. $\mathrm{Na}$ sequência, surgiram categorias iniciais (CI), que foram agrupadas a partir das semelhanças identificadas entre as mesmas, o que originou as categorias finais: a) formação continuada; b) professores: formação e o ato reflexivo; c) formação, função e saberes do coordenador pedagógico; e d) relação coordenador-professor.

Para auxiliar na reflexão e dar suporte teórico à criação dos metatextos de cada categoria, selecionamos pesquisadores que, de maneira magistral, abordam as temáticas discutidas. Destarte, para a categoria a, foram usufruídas as concepções de Imbernón (2011) e Tardif (2002). Na categoria b,surge a ótica reflexiva de Alarcão (2011), Libâneo (2012), Schön (1995) e Pimenta (2012). Na categoria c, os pressupostos de Domingues (2014), Lück (2014) e Saviani (2002) foram abordados. E, por fim, na última categoria- d-, utilizamos os estudos de Nóvoa (1995; 2017), Mahoney e Almeida (2005), os quais discorrem acerca da teoria do desenvolvimento de Wallon, e Vigotski (2008).

\section{Dialogar e refletir: análise das categorias de pesquisa}

Neste estágio da pesquisa, expomos o segundo momento do ciclo da ATD: o desenvolvimento das unidades de sentido em relações de significados que geraram a categorização. As produções que compõem o corpus desta pesquisa são apresentadas nos Quadros 1 e 2, organizadas de forma cronológica decrescente e identificadas com códigos: A se refere a artigos, D são dissertações e T representa as teses. Essas letras estão acrescidas de números para diferenciá-las no decorrer do presente estudo. 
Quadro 1- Produções encontradas no Portal de Periódicos da Coordenação de Aperfeiçoamento de Pessoal de Nível Superior e sua inserção nas categorias de análise: a) formação continuada; b) professores: formação e o ato reflexivo; c) formação, função e saberes do coordenador pedagógico; d) relação coordenador-professor

\begin{tabular}{|c|c|c|c|c|c|c|c|}
\hline \multirow{2}{*}{ CÓD. } & \multirow{2}{*}{ ARTIGO } & \multirow{2}{*}{ AUTOR } & \multirow{2}{*}{$\begin{array}{l}\text { PERIÓDICOS/ } \\
\text { PERÍODO } \\
\text { (2010-2020) }\end{array}$} & \multicolumn{4}{|c|}{ CATEGORIAS } \\
\hline & & & & $\mathbf{A}$ & B & $\mathbf{C}$ & D \\
\hline A1 & $\begin{array}{l}\text { O despertar do coordenador pedagógico } \\
\text { para a formação continuada docente }\end{array}$ & $\begin{array}{l}\text { AQUINO, J. M. B.; } \\
\text { FREIRE; M. L. E. }\end{array}$ & $\begin{array}{l}\text { Brazilian Journal of } \\
\text { Development } \\
\text { (2018) }\end{array}$ & $\mathrm{X}$ & & $\mathrm{X}$ & \\
\hline A2 & $\begin{array}{c}\text { Por que ensino como ensino? Contextos e } \\
\text { narrativas da trajetória de um professor } \\
\text { formador de professores }\end{array}$ & LIMA, F. J. & $\begin{array}{l}\text { HOLOS } \\
(2018)\end{array}$ & & $X$ & & \\
\hline A3 & $\begin{array}{l}\text { O professor coordenador: encontros de } \\
\text { trabalho coletivo e a formação continuada }\end{array}$ & $\begin{array}{l}\text { FERRI, T. H. J. B.; } \\
\text { BENITES, L. C.; } \\
\text { NETO, S. S. }\end{array}$ & $\begin{array}{c}\text { Revista Educação e } \\
\text { Cultura } \\
\text { Contemporânea } \\
(2016)\end{array}$ & $\mathrm{X}$ & & & \\
\hline A4 & $\begin{array}{l}\text { O que revelam as pesquisas sobre a } \\
\text { atuação do coordenador pedagógico }\end{array}$ & $\begin{array}{l}\text { MIZIARA, L. A. } \\
\text { S.; RIBEIRO, R.; } \\
\text { BEZERRA, G. F. }\end{array}$ & $\begin{array}{l}\text { RBEP } \\
(2014)\end{array}$ & & & $\mathrm{X}$ & \\
\hline
\end{tabular}

Fonte: Dados da pesquisa (2021).

Quadro 2- Produções encontradas na Biblioteca Digital Brasileira de Teses e Dissertações e sua inserção nas categorias de análise: a) formação continuada; b) professores: formação e o ato reflexivo; c) formação, função e saberes do coordenador pedagógico; d) relação coordenador-professor

\begin{tabular}{|c|c|c|c|c|c|c|c|c|}
\hline \multirow{2}{*}{ CÓD. } & \multirow{2}{*}{ TÍTULO } & \multirow{2}{*}{ AUTOR } & \multirow{2}{*}{ ESTUDO } & \multirow{2}{*}{ LOCAL } & \multicolumn{4}{|c|}{ CATEGORIAS } \\
\hline & & & & & $\mathbf{A}$ & $\mathbf{B}$ & $\mathbf{C}$ & D \\
\hline D1 & $\begin{array}{l}\text { O fazer de formador e de acompanhamento } \\
\text { pedagógico do coordenador pedagógico }\end{array}$ & \begin{tabular}{|c|} 
Thays Roberta \\
de Abreu \\
Gonzaga \\
Sentoma
\end{tabular} & Dissertação & PUC-SP & & & $X$ & \\
\hline D2 & $\begin{array}{l}\text { O coordenador pedagógico: experiências e } \\
\text { saberes de formação na perspectiva de } \\
\text { professores na Educação Infantil }\end{array}$ & $\begin{array}{c}\text { Larissa } \\
\text { Kenschikowsky }\end{array}$ & Dissertação & PUC-SP & & & $X$ & \\
\hline D3 & $\begin{array}{l}\text { O coordenador pedagógico e as relações } \\
\text { afetivas promotoras do desenvolvimento }\end{array}$ & $\begin{array}{l}\text { Tatiana Alves } \\
\text { Lara Volpe }\end{array}$ & Dissertação & PUC-SP & & & & $\mathrm{X}$ \\
\hline D4 & $\begin{array}{c}\text { O coordenador escolar e a formação } \\
\text { continuada de professores nas escolas de } \\
\text { Ensino Médio da Crede Jaguaribe-CE: } \\
\text { Limites e potencialidades } \\
\end{array}$ & $\begin{array}{l}\text { Cleomar Maciel } \\
\text { de Araújo Vieira }\end{array}$ & Dissertação & UFJF & & & $\mathrm{X}$ & \\
\hline $\mathrm{T} 5$ & $\begin{array}{c}\text { A mediação do coordenador pedagógico no } \\
\text { desenvolvimento profissional de professores } \\
\text { que ensinam Matemática }\end{array}$ & $\begin{array}{l}\text { Juliane do } \\
\text { Nascimento } \\
\text { Mosquini }\end{array}$ & Tese & Unesp & & $\mathrm{X}$ & $X$ & \\
\hline D6 & $\begin{array}{l}\text { A formação continuada do coordenador } \\
\text { pedagógico e o trabalho de formação junto } \\
\text { aos professores especialistas }\end{array}$ & $\begin{array}{l}\text { Leonardo Felipe } \\
\text { Paes Monteiro }\end{array}$ & Dissertação & UFSCar & & & $X$ & \\
\hline D7 & $\begin{array}{c}\text { A organização do ensino em módulos em } \\
\text { uma EMEF de São Paulo: aprendizagens dos } \\
\text { professores acerca da proposta e o papel } \\
\text { formador do coordenador pedagógico }\end{array}$ & $\begin{array}{l}\text { Daniela Palma } \\
\text { Coelho }\end{array}$ & Dissertação & PUC-SP & $\mathrm{X}$ & & & \\
\hline D8 & O papel do coordenador pedagógico na & Elizabeth & Dissertação & PUC-SP & & & $X$ & \\
\hline
\end{tabular}




\begin{tabular}{|c|c|c|c|c|c|c|c|c|}
\hline & $\begin{array}{l}\text { formação crítica de professores: } \\
\text { contribuições e desafios }\end{array}$ & $\begin{array}{l}\text { Tagliatella } \\
\text { Orfão }\end{array}$ & & & & & & \\
\hline D9 & $\begin{array}{l}\text { O papel do(a) professor(a) coordenador(a) } \\
\text { pedagógico(a) na formação em serviço } \\
\text { dos(as) docentes no Ensino Fundamental II: } \\
\text { uma análise dessa função em uma rede } \\
\text { municipal de ensino do interior paulista }\end{array}$ & $\begin{array}{l}\text { Carolina Alves } \\
\text { de Oliveira }\end{array}$ & Dissertação & UFSCar & & & & $\mathrm{X}$ \\
\hline D10 & $\begin{array}{c}\text { Escuta de professores e professoras sobre os } \\
\text { sentidos da atuação do coordenador } \\
\text { pedagógico na formação continuada centrada } \\
\text { na escola }\end{array}$ & $\begin{array}{l}\text { Lindinalva } \\
\text { Ferreira de } \\
\text { Queiroz }\end{array}$ & Dissertação & UFPE & & $\mathrm{X}$ & & $\mathrm{X}$ \\
\hline D11 & $\begin{array}{l}\text { O coordenador pedagógico e a formação } \\
\text { continuada de professores em serviço: uma } \\
\text { análise em escolas públicas da região } \\
\text { metropolitana do estado do Sergipe }\end{array}$ & $\begin{array}{l}\text { Mariana Muniz } \\
\text { Sampaio }\end{array}$ & Dissertação & UFS & & & & $\mathrm{X}$ \\
\hline D12 & $\begin{array}{l}\text { O coordenador pedagógico e a formação de } \\
\text { professores alfabetizadores no município de } \\
\text { São Paulo }\end{array}$ & $\begin{array}{l}\text { Renata Lívia } \\
\text { Soares Perini }\end{array}$ & Dissertação & USP & & & $\mathrm{X}$ & \\
\hline D13 & $\begin{array}{c}\text { Ressignificação do trabalho do coordenador } \\
\text { pedagógico no redimensionamento da } \\
\text { formação continuada em âmbito escolar }\end{array}$ & Márcia Fabris & Dissertação & UFFS & & & $\mathrm{X}$ & $\mathrm{X}$ \\
\hline D14 & $\begin{array}{c}\text { A formação contínua docente na rede } \\
\text { pública estadual paulista: As relações entre o } \\
\text { professor coordenador do Núcleo } \\
\text { Pedagógico, o professor coordenador e o } \\
\text { professor }\end{array}$ & $\begin{array}{l}\text { Adelina Braga } \\
\text { Matsuda }\end{array}$ & Dissertação & Unifesp & & & & $\mathrm{X}$ \\
\hline D15 & $\begin{array}{c}\text { O potencial de um grupo colaborativo para a } \\
\text { constituição do professor coordenador como } \\
\text { formador de docentes }\end{array}$ & $\begin{array}{l}\text { Kátia Martins } \\
\text { Rodrigues }\end{array}$ & Dissertação & PUC-SP & & & $X$ & \\
\hline D16 & $\begin{array}{l}\text { O coordenador pedagógico como agente de } \\
\text { mudanças na prática docente }\end{array}$ & $\begin{array}{l}\text { Elisangela } \\
\text { Carmo de } \\
\text { Oliveira }\end{array}$ & Dissertação & PUC-SP & & & $X$ & \\
\hline D17 & $\begin{array}{l}\text { Concepções de coordenadores pedagógicos } \\
\text { acerca da sua formação continuada, e } \\
\text { desenvolvimento profissional: um estudo de } \\
\text { caso em uma escola da rede pública } \\
\text { municipal de educação de Sobral-CE } \\
\end{array}$ & $\begin{array}{l}\text { Liduina Maria } \\
\text { Gomes }\end{array}$ & Dissertação & Uece & $\mathrm{X}$ & & $X$ & \\
\hline D18 & $\begin{array}{l}\text { A função do coordenador pedagógico na } \\
\text { qualificação do trabalho docente: formação } \\
\text { continuada e avaliação educacional }\end{array}$ & $\begin{array}{l}\text { Elizabeth } \\
\text { Feffermann }\end{array}$ & Dissertação & PUC-SP & & & $X$ & \\
\hline D19 & $\begin{array}{c}\text { A atuação do coordenador pedagógico na } \\
\text { formação de professores das escolas } \\
\text { municipais de Educação Infantil (E.M.E.I.s) } \\
\text { de São Paulo }\end{array}$ & $\begin{array}{c}\text { Vivian de } \\
\text { Andrade Torres } \\
\text { Machado }\end{array}$ & Dissertação & PUC-SP & & & $\mathrm{X}$ & \\
\hline D20 & $\begin{array}{c}\text { Vivências do coordenador pedagógico } \\
\text { iniciante no contexto escolar: sentidos e } \\
\text { significados mediando a constituição de uma } \\
\text { identidade profissional }\end{array}$ & $\begin{array}{c}\text { Silvana Faria de } \\
\text { Melo }\end{array}$ & Dissertação & Unitau & & & $X$ & \\
\hline D21 & $\begin{array}{l}\text { A formação continuada docente no } \\
\text { espaço/tempo da coordenação pedagógica }\end{array}$ & Josimara Xavier & Dissertação & UnB & $\mathrm{X}$ & & & \\
\hline D22 & $\begin{array}{c}\text { Formação docente, professor coordenador } \\
\text { pedagógico e contexto escolar: diálogos } \\
\text { possíveis }\end{array}$ & $\begin{array}{l}\text { Osmar Hélio } \\
\text { Alves Araújo }\end{array}$ & Dissertação & UFC & $\mathrm{X}$ & & $X$ & \\
\hline D23 & $\begin{array}{c}\text { A coordenação pedagógica e a práxis } \\
\text { educativa na escola }\end{array}$ & $\begin{array}{c}\text { Marilda da Silva } \\
\text { Rudnick }\end{array}$ & Dissertação & UFMT & & & $\mathrm{X}$ & $\mathrm{X}$ \\
\hline
\end{tabular}


Revista de Educação, Ciência e Tecnologia

\begin{tabular}{|c|c|c|c|c|c|c|c|}
\hline D24 & $\begin{array}{c}\text { Professor coordenador na formação contínua } \\
\text { de professores: um estudo em escolas do } \\
\text { município de Limeira }\end{array}$ & $\begin{array}{l}\text { Luciana Estessi } \\
\text { Bento Antunes }\end{array}$ & Dissertação & Unesp & $\mathrm{X}$ & & \\
\hline D25 & $\begin{array}{c}\text { A formação continuada na perspectiva das } \\
\text { coordenadoras pedagógicas de creches } \\
\text { municipais de Fortaleza }\end{array}$ & $\begin{array}{l}\text { Maria Ilnair } \\
\text { Martins Leite }\end{array}$ & Dissertação & UFC & & & X \\
\hline T26 & $\begin{array}{c}\text { O coordenador pedagógico e a ação docente: } \\
\text { contribuições de uma política pública de } \\
\text { desenvolvimento profissional no local de } \\
\text { trabalho }\end{array}$ & $\begin{array}{c}\text { Nilza Donizetti } \\
\text { Dias Ferreira }\end{array}$ & Tese & UPM & $\mathrm{X}$ & & \\
\hline D27 & $\begin{array}{l}\text { Coordenador pedagógico e os } \\
\text { condicionantes do ser e do vir a ser um } \\
\text { formador }\end{array}$ & $\begin{array}{c}\text { Débora Rana de } \\
\text { Camargo }\end{array}$ & Dissertação & PUC-SP & & & $\mathrm{X}$ \\
\hline D28 & $\begin{array}{c}\text { Formação em serviço de professores em } \\
\text { escolas municipais do extremo leste da } \\
\text { capital paulista }\end{array}$ & Vinicius Tavano & Dissertação & UPM & & & $\mathrm{X}$ \\
\hline D29 & $\begin{array}{c}\text { Os desafios do professor coordenador } \\
\text { pedagógico na formação continuada dos } \\
\text { docentes do Ensino Fundamental: o caso da } \\
\text { região do Vale do Ribeira/SP }\end{array}$ & $\begin{array}{l}\text { Vania Ida } \\
\text { Malavasi dos } \\
\quad \text { Santos }\end{array}$ & Dissertação & Umesp & & & $\mathrm{X}$ \\
\hline D30 & $\begin{array}{c}\text { O impacto da formação continuada de } \\
\text { professores nas escolas com bom } \\
\text { desempenho em Matemática: o caso da rede } \\
\text { escolar SESI-SP }\end{array}$ & $\begin{array}{l}\text { Dimas Cássio } \\
\text { Simão }\end{array}$ & Dissertação & PUC-SP & $X$ & & \\
\hline D31 & $\begin{array}{l}\text { O papel do coordenador pedagógico na } \\
\text { formação dos professores }\end{array}$ & Adalberto Silva & Dissertação & Umesp & & & $\mathrm{X}$ \\
\hline D32 & $\begin{array}{l}\text { Ação da coordenação pedagógica e a } \\
\text { formação continuada dos professores do } \\
\text { Ensino Fundamental I: desafios e } \\
\text { possibilidades }\end{array}$ & $\begin{array}{l}\text { Silvana } \\
\text { Aparecida } \\
\text { Santana } \\
\text { Tamassia }\end{array}$ & Dissertação & PUC-SP & & & X \\
\hline D33 & $\begin{array}{l}\text { O coordenador pedagógico e o seu papel na } \\
\text { formação continuada em serviço do } \\
\text { professor de Educação Infantil (creche) }\end{array}$ & $\begin{array}{l}\text { Viviani } \\
\text { Aparecida } \\
\text { Amabile } \\
\text { Zumpano }\end{array}$ & Dissertação & PUC-SP & $\mathrm{X}$ & & X \\
\hline D34 & $\begin{array}{l}\text { Sou CP na Educação Infantil, e agora? } \\
\text { Um estudo sobre o papel do coordenador } \\
\text { pedagógico como formador de professores }\end{array}$ & $\begin{array}{l}\text { Neli Regina } \\
\text { Palliares }\end{array}$ & Dissertação & Umesp & & & X \\
\hline D35 & $\begin{array}{c}\text { Sobre a ação docente: os sentidos dados ao } \\
\text { planejamento e à formação continuada por } \\
\text { professores de uma escola pública municipal } \\
\text { de Natal/RN }\end{array}$ & $\begin{array}{l}\text { Jailma } \\
\text { Cavalcante } \\
\text { Barauna }\end{array}$ & Dissertação & UFRN & & $\mathrm{X}$ & \\
\hline
\end{tabular}

Fonte: Dados da pesquisa (2021).

No Quadro 2 é possível perceber que as pesquisas realizadas na Pontifícia Universidade Católica de São Paulo (PUC-SP) representam aproximadamente $37 \%$ dos trabalhos selecionados. Outro fator relevante é a categoria predominante, em que a maior parte dos estudos se refere à formação, função e saberes do coordenador pedagógico (categoria C). Além disso, foi analisado o aspecto temporal das publicações selecionadas para análise, o qual está exposto na Tabela 3. 
Tabela3 - Ano das publicações selecionadas, com os respectivos códigos elencados:

A (artigo), D (dissertação), e T (tese)

\begin{tabular}{l|c|c}
\hline ANO & PESQUISAS & TOTAL \\
\hline 2010 & D33, D34 e D35 & 3 \\
2011 & D32 & 1 \\
2012 & D28, D29, D30 e D31 & 4 \\
2013 & D25, T26 e D27 & 3 \\
2014 & A4, D23 e D24 & 3 \\
2015 & D19, D20, D21 e D22 & 4 \\
2016 & A3 e D18 & 2 \\
2017 & D15, D16 e D17 & 3 \\
2018 & A1, A2, D6, D7, D8, D9, D10, D11, D12, D13 e D14 & 11 \\
2019 & D2, D3, D4 e T5 & 4 \\
2020 & D1 & 1 \\
\hline
\end{tabular}

Fonte: Dados da pesquisa (2021).

Com o suporte dessa tabela, é possível perceber que a maior parte das pesquisas, alinhadas ao foco deste artigo, foram publicadas no ano de 2018. Para dar sequência à análise, apresentamos a seguir os argumentos elaborados a partir do terceiro ponto do ciclo da ATD, que é a captação do novo emergente. Cabe ressaltar que a construção dos metatextos expressa os entendimentos alcançados a partir do conjunto de textos que formam cada categoria, os quais dialogam reflexivamente com estudiosos relevantes para cada temática.

\subsection{Formação continuada}

$\mathrm{Na}$ categoria "formação continuada" encontra-se um artigo, sete dissertações e uma tese: A3, D7, D17, D21, D22, D24, T26, D30 e D33. Tais trabalhos ressaltam que, diferente da formação inicial do professor, que acontece no espaço universitário, existe a formação continuada, que ocorre durante a prática docente, ou seja, enquanto o profissional está atuando no local de trabalho, a escola. Além da formação in loco,são também veementemente significativas as formações que acontecem na Pós-Graduação, nos cursos de extensão universitária e até mesmo no momento em que um livro, vídeo e/ou bate-papo se tornam aliados para aperfeiçoar a constituição e o desenvolvimento do professor. Esse ato formativo visa a melhorar o sistema de ensino diante dos efeitos da sociedade, com o intuito de qualificar as identificações dos saberes com os fazeres discente e docente.

Sabemos que há uma necessidade constante de que os professores acompanhem as mudanças do sistema de ensino, que continuamente sofre modificações. Nesse viés, o artigo 67 da Lei de Diretrizes e Bases da Educação Nacional (LDB) pontua que:

Os sistemas de ensino promoverão a valorização dos profissionais da educação, assegurando-lhes, inclusive nos termos dos estatutos e dos planos de carreira do magistério público: 
I - ingresso exclusivamente por concurso público de provas e títulos;

II - aperfeiçoamento profissional continuado, inclusive com licenciamento periódico remunerado para esse fim;

III - piso salarial profissional;

IV - progressão funcional baseada na titulação ou habilitação, e na avaliação do desempenho;

V - período reservado a estudos, planejamento e avaliação, incluído na carga de trabalho;

VI - condições adequadas de trabalho (BRASIL, 2017, art. 67).

Enquanto ser cultural, no decorrer da história o ser humano desenvolveu novas complexidades, e fez com que a educação também se tornasse mais heterogênea. Assim, defendemos que os professores precisam compreender as incessantes mudanças que ocorrem e influenciam suas práticas profissionais. Isso se configura como um motivo para o docente buscar uma formação permanente no decorrer da sua atuação como mediador do ensino escolar.

O ensino escolar é um contexto amplo, que requer inovações constantes, com vistas a valorizar tanto os alunos quanto a própria qualificação profissional, mas, para que isso ocorra de fato, o professor precisa entender que ensinar vai além de desenvolver competências e habilidades. Esse ato envolve fomentar experiências de mundo que são indispensáveis para instigar nos alunos o interesse pelos conteúdos e o desenvolvimento da cognição, da autonomia e da cidadania.

Nesse sentido, compreendemos que a formação in loco fornece subsídios para que o profissional do ensino, o professor, entenda e problematize as condutas que sua demanda de alunos requer.A formação continuada é um direito dos docentes e, nesta premissa, Xavier (2015, p. 47) acredita que "a formação continuada docente, atividade com uma especificidade própria de transformar situações, pode contribuir para transformar mentes que transformarão a humanidade".É a essa concepção de transformação socioeducativa que Simão (2012, p. 34) também se refere em sua dissertação, destacando que

\footnotetext{
A formação continuada, então, pode ser entendida como um processo que visa a proporcionar o desenvolvimento profissional do professor mediante a associação entre teoria e prática e a oportunidade de trocas de experiências, criando condições de trazer mudanças na sua prática pedagógica e consequentemente alcançar um ensino e uma aprendizagem de maior qualidade.
}

Tardif (2002) afirma que o professor precisa levar em consideração os saberes relativos às experiências profissionais, mas que, sobretudo, ele precisa compreender que estes saberes irão se modificar, pois eles são temporais, plurais, heterogêneos, personalizados e situados. É a partir desse conjunto de possibilidades e transformações que a formação continuada se faz indispensável. Por conseguinte, precisa ser organizada de forma a considerar o contexto real dos estudantes, posto que eles são o objeto do trabalho docente, garantindo que o professor planeje suas ações com base naquilo que é pertinente ao ambiente escolar em que se insere.

Ser professor requer ética e moral, pois é uma responsabilidade que influencia outros humanos (IMBERNÓN, 2011). O comprometimento desse profissional se diferencia quando há o entendimento de que não há padrões a serem seguidos, mas valores que precisam ser notados e alinhados no exercício da promoção educativa da sua profissão: a autonomia e a evolução constante. 
A escola, como espaço de ação docente, é enfatizada nos estudos dessa categoria como aquele que traz as significações mais importantes e necessárias à prática do professor; afinal, está centrado nas ideologias, nas crenças e nos valores dos sujeitos que circulam por essa atmosfera de aprendizes. Imbernón (2011) explica que o docente precisa de aprendizagens originais para conseguir exercer e realizar o seu trabalho e a formação dos alunos. Contribuir para o seu desenvolvimento no âmbito do trabalho, portanto, deve ser o objetivo principal das instituições de ensino, ou seja, não há outra maneira de sofisticar as práticas educativas docentes senão pelas formações continuadas.

A educação exige um profissional comprometido e responsável com os seus afazeres educativos e sociais. A responsabilidade do professor se entende para além de ensinar seus alunos a dominar conteúdos, pois seu maior comprometimento deve estar em abrir horizontes para que os estudantes desenvolvam a capacidade de pensar e agir como cidadãos ativos na sociedade. Acreditamos, veementemente, que a partir de uma formação continuada in loco isso possa ser oportunizado de modo mais qualitativo pelos professores. O docente precisa de novos olhares para entender cada sujeito, que envolve uma necessidade de estudos, e que denota à formação continuada de professores a devida importância.

\subsection{Professores: formação e o ato reflexivo}

As pesquisas A2, T5, D10 e D35 possuem foco na formação e no ato reflexivo dos professores. Neste contexto, pensar no que é ser um professor reflexivo é ter alicerce para desenvolver ideias que, muitas vezes, se encontram abandonadas nas práticas pedagógicas e não fazem parte do cotidiano escolar. Para iniciar a fundamentação desta categoria, tomamos emprestado o questionamento de Pimenta (2012):Professor reflexivo- adjetivo ou conceito?Nessa pergunta, há duas concepções que podemos compreender: refletir é um atributo do professor, e esse atributo se tornou um conceito muito estudado (PIMENTA, 2012).

O professor reflexivo é o profissional que atua de maneira criativa, revolucionária e que compreende a importância de organizar suas práticas com base na coletividade e na diferença presentes no espaço educativo. Segundo Alarcão (2011), esse sujeito não organiza práticas reprodutoras e não utiliza ideias exteriores para uma perspectiva diferente de planejamento, afinal, ele domina o conhecimento e possui a capacidade de reorganizá-lo conforme as condições do próprio contexto em que se insere.

Ponderar acerca desta temática sem manifestar as pesquisas de Schön (1930-1997) seria um ato falho. Schön foi o grande pedagogo estadunidense que formulou ideias e conceitos sobre o professor reflexivo. Tal concepção pauta-se principalmente naquele sujeito que aprende fazendo; ou seja, trata-se de um profissional que observa, analisa e reflete sobre as suas práticas pedagógicas no intuito de se aperfeiçoar, qualificar e contribuir com os seus alunos para um ensino mais eficaz (SHIGUNOV NETO; FORTUNATO, 2017).

Alarcão (2011), assim como Schön (1995), manifesta que é indispensável criar e organizar condições de práticas reflexivas na escola, pois o professor precisa sentir-se envolvido e instigado a pensar. Dessa forma, Schön (1995, p. 87) ressalta que "[...] os responsáveis escolares que queiram encorajar os professores a tornarem-se profissionais reflexivos devem tentar criar espaços de liberdade tranquila onde a reflexão-na-ação seja possível”.

Pimenta (2012) discute na sua obra a ótica schöniana, e menciona que os currículos de formação de professores precisam estar ancorados nessa concepção para propiciar a capacidade de reflexão aos profissionais envolvidos. O professor, quando capacitado para 
pesquisar sobre a sua própria prática e então refletir com essa pesquisa, está potencializando a sua identidade profissional e significando a educação.

Fundamentadas na leitura dos trabalhos sobre formação e ato reflexivo do professor, nos deparamos com uma frase na pesquisa A2, que reflete as ideias supracitadas: "A falta de reflexão do professor sobre sua prática pedagógica pode garantir a repetição de um ensino destituído de significado para os alunos" (LIMA, 2018, p. 273). Por esse ângulo,Schön (1995) comenta que observar o desempenho dos estudantes é, sem dúvidas, oportuno, porque transmite informações mais valiosas que as palavras, embora a observação de nada adiantará se não houver uma interpretação crítica.

Nesse sentido, é possível compreender que o ato reflexivo permite que os sujeitosnesse caso, os professores-tenham a desenvoltura de enriquecer suas práticas pedagógicas a partir de suas próprias ações. Assim, pode modificá-las ao reconhecer a realidade na qual vive e quais são, de fato, os valores a serem considerados para a reorganização de sua conduta didático-pedagógica coletiva e individual.

Ao refletirmos sobre a reorganização coletiva, estaremos emitindo uma realidade que precisa ser considerada nas perspectivas comuns. Libâneo (2012) explica que é um dos ideais que precisa ser considerado comum, e escreve que "é preciso a reflexividade comunitária, a reflexividade compartilhada, num esforço de instaurar nas escolas uma prática de gestão e convivência lastreada na construção de significados e entendimentos compartilhados a partir das diferenças e na busca de valores universais comuns" (p. 90-91).

A prática reflexiva coletiva é intrínseca à gestão da sala de aula, em razão de que é esse exercício que impulsiona e permite que o docente passe pela experiência de fazer uma autoavaliação de suas ações, metodologias e estratégias de ensino. A reflexividade resulta em considerações de minúcias que precisam ser reexaminadas para as mudanças de planos e para incorporar os subsídios necessários que antes não estavam presentes na atividade pedagógica.

Não há dúvidas de que a prática reflexiva é valiosa, pois é uma epistemologia da práxis educativa, a qual trata da prática e da teoria, contextos que são inseparáveis e igualmente necessários para a formação do professor e para a sua qualificada desenvoltura na área de atuação. Essa pauta serve de âncora para o desenvolvimento profissional; com ela a reflexão se fará presente, no sentido de amparar e orientar a construção de um conhecimento pautado na realidade,sobre a qual o professor irá contestar de maneira dialética-reflexiva.

\subsection{Formação, função e saberes do coordenador pedagógico}

Nessa categoria foram elencadas 26 pesquisas que se entrelaçam, com o objetivo de apresentar compreensões sobre o coordenador pedagógico, quais são: A1, A4, D1, D2, D4, T5, D6, D8, D12, D13, D15, D16, D17, D18, D19, D20, D22, D23, D25, D27, D28, D29, D31, D32, D33 e D34. Como comentado anteriormente, este tópico possui a maior quantidade de trabalhos - mais da metade -, os quais buscam identificar a formação, as funções e os saberes do coordenador pedagógico.

A profissão do coordenador pedagógico é recente, embora suas atribuições estejam explícitas há muito tempo por meio de diversos momentos da história da Educação. Além disso, muitos estudos foram necessários para chegar a essa profissão, assim como mudanças e políticas públicas educacionais, que amparam esse profissional e oferecem base para a compreensão de suas funções e de sua formação.

O trabalho do coordenador pedagógico existe, historicamente, desde a educação jesuíta,instaurada no Brasil no ano de 1549. Desde então, percebe-se como sendo suas 
funções a supervisão, a orientação e a organização de estudos. Durante o período jesuíta, o trabalho desse profissional era realizado pelo prefeito dos estudos (SAVIANI, 2002). Com o decorrer do tempo, novas nomenclaturas foram criadas até essa que conhecemos atualmente.

O trabalho A4 salienta aspectos sobre a formação, funções e saberes do coordenador pedagógico, pois apresenta uma revisão de literatura para identificar pesquisas referentes à atuação desse profissional e aos avanços com o ecoar da profissão (MIZIARA; RIBEIRO; BEZERRA, 2014). No artigo, os autores ressaltam que: "É competência do coordenador criar condições favoráveis que possibilitem aos professores relacionar criticamente suas experiências com os saberes acadêmicos, num espaço de problematizações consequentes e interlocuções democráticas" (MIZIARA; RIBEIRO; BEZERRA, 2014, p. 622).

Domingues (2014) faz, na introdução do seu livro O coordenador pedagógico: a formação contínua do docente na escola, um apanhado das funções desse profissional. Entre a gama de atribuições, estão referidas a organização de reuniões pedagógicas, o acompanhamento ao trabalho do professor na sala de aula, o cuidado da avaliação do corpo docente e a organização de formações continuadas ofertadas ao professor na instituição escolar.Para que seu papel de formador, mediador, líder e motivador de professores seja efetuado com sucesso,o profissional da gestão pedagógica necessita estar em contato e atento àquilo que docentes realizam nas salas de aula, bem como analisar as premissas dos alunos para poder dar feedbacks aos professores.

O exercício de liderança faz parte da educação, pois está relacionado à ação formativa dos professores. Lück (2014) dá ênfase em suas pesquisas sobre a gestão escolar como prática de liderança, ao estabelecer que os membros dessa equipe influenciam sujeitos para o processo de nutrir competências profissionais para um ensino e uma aprendizagem efetivos. Em suas palavras, a liderança é "um conjunto de ações, atitudes e comportamentos assumidos por uma pessoa, para influenciar o desempenho de alguém, visando a realização de objetivos organizacionais" (LÜCK, 2014, p. 95).

Durante as leituras, foi possível perceber que algumas expressões se repetiram na maioria dos trabalhos: melhorar o ensino, qualificar a aprendizagem, contribuir para a melhoria da aprendizagem dos alunos, dentre outras similares. Nessa concepção, tais afirmativas evidenciam que o trabalho do coordenador pedagógico possibilita muitos benefícios para a instituição, tanto para os docentes quanto para os discentes.

Sobre isso, Mosquini $(2019$, p. 45) frisa que "sem domínio de conhecimentos teóricometodológicos a respeito do processo de ensino e aprendizagem, o trabalho do coordenador pode não cooperar para a melhoria da qualidade de ensino na escola". Nesse sentido, da mesma maneira que precisam pensar, organizar e mediar momentos de formação para os professores, os coordenadores também carecem de desenvolvimento profissional contínuo, pois sem capacitação adequada não serão capazes de socializar conhecimentos e motivar os professores a se qualificarem.

\subsection{Relação coordenador-professor}

O fato é que todas as boas relações no âmbito social beneficiam uns aos outros, e a relação coordenador-professor não é diferente. O ponto central das pesquisas D3, D9, D10, D11, D13, D14, D23 e D32 é a relação entre esses dois profissionais, o que reforça a ideia do quão importante ela é para a educação escolar.

O coordenador pedagógico assume o papel de liderança na gestão escolar, e cabe a ele administrar a sua própria relação com os professores. Além disso, é seu dever favorecer um 
bom relacionamento entre docentes (VOLPE, 2019). Essa relação é determinante para que suas atribuições na escola tenham um desfecho impulsionador entre os pares na atuação docente.

Conforme a relação entre o professor e o coordenador se fortalece, ambos crescem na práxis e estabelecem vínculos de confiança um com o outro. Dessa maneira, esses profissionais criam parceria de cooperação para que o trabalho em equipe se torne cada vez mais eficiente e significativo. Essa relação dinâmica da equipe possibilita a construção de pontes para alcançar os objetivos propostos com maior facilidade e empenho, uma vez que o esforço coletivo é condição para a formação humana do aluno.Quando o professor e o coordenador compartilham momentos dialógicos dentro do ambiente escolar, o produto dessa relação é o ensino qualificado; todavia, o resultado será negativo se essa relação não for prazerosa.

Sem o cultivo de uma parceria educativa, será difícil organizar momentos de formação,assim como promover boas transformações na práxis (SAMPAIO, 2018). A prazerosa relação é vista como ponto-chave para a participação ativa dos professores, que se entenderão como pesquisadores intelectuais da sua prática e se sentirão motivados a participar das formações continuadas,organizadas e propiciadas pelo seu parceiro, o coordenador pedagógico.

Vigotski (2008, p. 24) afirma que "o verdadeiro curso do desenvolvimento do pensamento não vai do individual para o socializado, mas do social para o individual”. Desse modo, o social que apresentamos é a relação entre docente e gestão, em que um pode e deve favorecer as ideias do outro, para que se desenvolvam de forma subjetiva, mas visando a construção de um coletivo educacional. O coordenador pedagógico precisa se relacionar com a sua equipe de professores, de modo a demonstrar e fornecer apoio, pois assim poderá despertar uma relação segura e que se sintonize com o objetivo de desenvolver uma aprendizagem qualificada nos estudantes. Agrupar esforços é saber agir com competência e agilidade em prol de todos, tendo em vista o que é melhor para os alunos e para a formação profissional daqueles que optaram por fazer parte do magistério.

Não é possível formar médicos sem a presença de outros médicos e, da mesma forma, isso ocorre no caso dos professores, visto que se formam junto a outros professores, podendo contar com eles e com a gestão pedagógica (NÓVOA, 2017). Nóvoa (2017, p. 1.123) enfatiza, nessa mesma perspectiva, que "é na colaboração, nas suas potencialidades para a aprendizagem e nas suas qualidades democráticas, que se definem os percursos formativos".

O relacionamento afetivo entre professor e coordenador pedagógico gera um trabalho confiável e aberto, que permite o compartilhamento de ideias com comprometimento e sem rigidez. Para Wallon, a afetividade faz parte do desenvolvimento pessoal e da interação entre os sujeitos (MAHONEY; ALMEIDA, 2005). Durante suas colocações, Wallon abordou que os processos de ensino e de aprendizagem serão melhor desenvolvidos, de acordo com seu conceito de afetividade para o desenvolvimento social e cognitivo, no momento em que forem permitidas discussões e expressões diante de uma ação solidária.

Não obstante, é importante que a coordenação pedagógica vá além de uma organização de momentos formativos, fazendo-se presente e interagindo em todos os instantes possíveis com os professores. Assim, criará uma relação coordenador-professor que irá reprimir a forma hierárquica e consolidar uma união afetuosa em prol do trabalho educativo coletivo. 


\section{Considerações Finais}

A finalidade deste artigo foi apresentar mapeamento de pesquisas que abordam o papel do coordenador pedagógico na formação continuada, que ocorre no ambiente escolar de docentes. Dessa forma, esse processo constitui-se, segundo a ATD, como "um processo autoorganizado", o qual gerou significados propiciados e construídos ao longo da realização das análises e contextualizações.

Retornamos ao questionamento principal: $\mathrm{O}$ que revelam as pesquisas, publicadas no período de 2010 a 2020, que têm como foco a investigação sobre a formação continuada de docentes na escola, sob a mediação dos coordenadores pedagógicos? Os artigos, dissertações e teses que fazem parte do corpus da revisão investigativa possibilitaram novos conhecimentos e demonstraram que,apesar do coordenador pedagógico ser uma nomenclatura da sociedade contemporânea, as funções que esse profissional desempenha são importantes desde a antiguidade.

O coordenador pedagógico é um líder da gestão escolar, e precisa de uma constituição profissional constante para que desenvolva suas tarefas com êxito. Para a organização e mediação de formações continuadas na escola, é inevitável que a cumplicidade e parceria façam parte da relação entre o coordenador pedagógico e o professor, afinal, ambos estão em busca de garantir a qualidade de ensino e de aprendizagem aos discentes.

Reconhecer-se como sujeito intelectual e pesquisador de suas próprias ações pedagógicas são compromisso e responsabilidade do docente, para conseguir oportunizar a formação humana e cidadã dos seus alunos. Diante disso, as formações continuadas in loco, mediadas pelo coordenador pedagógico, propiciam momentos de reflexões e são alicerces para o (re)pensar sobre as dimensões educativas conforme estas se transformam. Ademais, essas formações contribuem no protagonismo da comunidade escolar, pois valorizam os saberes e fazeres educacionais dos sujeitos que fazem parte desse espaço.

\section{Referências}

ALARCÃO, Isabel. Professores reflexivos em uma escola reflexiva. 8. ed. São Paulo: Cortez, 2011.

ANTUNES, Luciana Estessi Bento. Professor coordenador na formação contínua de professores: um estudo em escolas do município de Limeira. 158 f. Dissertação (PósGraduação em Educação) - Universidade Estadual Paulista, Rio Claro, 2014.

AQUINO, José Mauro Braz de; FREIRE, Maria Luzivany Euzébio. O despertar do coordenador pedagógico para a formação continuada docente. Brazilian Journal of Development, Curitiba, v. 4, n. 5, p. 2433-2446, ago. 2018. Edição Especial.

ARAÚJO, Osmar Hélio Alves. Formação docente, professor coordenador pedagógico e contexto escolar: diálogos possíveis. 147 f. 2015. Dissertação (Pós-Graduação em Educação) - Universidade Federal do Ceará, Fortaleza, 2015.

BARAUNA, Jailma Cavalcante. Sobre a ação do docente: os sentidos dados ao planejamento e formação continuada por professores de uma escola pública municipal de Natal. 139 f. 2010. Dissertação (Pós-Graduação em Educação) - Universidade Federal do Rio Grande do Norte, Natal, 2010. 
BRASIL. Lei de diretrizes e bases da educação nacional. Brasília: Senado Federal, Coordenação de Edições Técnicas, 2017.

CAMARGO, Debora Rana de. Coordenador pedagógico e os condicionamentos do ser e do vir ser um formador. 188 f. 2013. Dissertação (Pós-Graduação em Educação) - Pontifícia Universidade Católica de São Paulo, São Paulo, 2013.

COELHO, Daniela Palma. A organização do ensino em módulos em uma EMEF de São Paulo: aprendizagens dos professores acerca da proposta e o papel formador do coordenador pedagógico. 147 f. 2018. Dissertação (Pós-Graduação em Educação) - Pontifícia Universidade Católica de São Paulo, São Paulo, 2018.

DOMINGUES, Isanede. O coordenador pedagógico e a formação continuada do docente na escola. São Paulo: Cortez, 2014.

FABRIS, Márcia. Ressignificação do trabalho do coordenador pedagógico no redimensionamento da formação continuada em âmbito escolar. 132f. 2018. Dissertação (Mestrado Profissional em Educação) - Universidade Federal da Fronteira Sul, Erechim, 2018.

FEFFERMANN, Elizabeth. A função do coordenador pedagógico na qualificação do trabalho docente: formação continuada e avaliação educacional. 152 f. 2016. Dissertação (Pós-Graduação em Educação) - Pontifícia Universidade Católica de São Paulo, São Paulo, 2016.

FERREIRA, Norma Sandra de Almeida. As pesquisas denominadas "estado da arte". Educação \& Sociedade, Campinas, v. 23, n. 79, p. 257-272, ago. 2002.

FERREIRA, Nilza Donizetii Dias. O coordenador pedagógico e a ação docente: contribuições de uma política pública de desenvolvimento profissional no local de trabalho. 217 f. 2013. Tese (Pós-Graduação em Educação, Arte e História da Cultura) - Universidade Presbiteriana Mackenzie, São Paulo, 2013.

FERRI, Thais Helena Jordao Bartiromo et al. O Professor Coordenador: encontros de trabalho coletivo e a formação continuada. Educação e Cultura Contemporânea, Rio de Janeiro, v. 13, n. 32, p. 22-41, jan. 2016.

GOMES, Liduina Maria. Concepções de coordenadores pedagógicos acerca da sua formação continuada, e desenvolvimento profissional: um estudo de caso em uma escola da rede pública municipal de educação de Sobral-CE. 120 f. 2017. Dissertação (PósGraduação em Educação) - Universidade Estadual do Ceará, Fortaleza, 2017.

IMBERNÓN, Francisco. Formação docente e profissional: formar-se para a mudança e a incerteza. 9. ed. São Paulo: Cortez, 2011.

KENSCHIKOWSKY, Larissa. O coordenador pedagógico: experiências e saberes de formação na perspectiva de professores na Educação Infantil. 105 f. 2019. Dissertação (PósGraduação em Educação) - Pontifícia Universidade Católica de São Paulo, São Paulo, 2019.

LEITE, Maria Ilnair Martins. A formação continuada na perspectiva das coordenadoras pedagógicas de creches municipais de Fortaleza. 106 f. 2013. Dissertação (Pós-Graduação em Educação) - Universidade Federal do Ceará, Fortaleza, 2013. 
LIBÂNEO, José Carlos. Reflexividade e formação de professores: outra oscilação do pensamento pedagógico brasileiro? In: PIMENTA, Selma Garrido; GHEDIN, Evandro (org.). Professor reflexivo no Brasil: gênese e crítica de um conceito. 7. ed. São Paulo: Cortez, 2012. p. 63-93.

LIMA, Francisco José de. Por que ensino como ensino? Contextos e narrativas da trajetória de um professor formador de professores. Holos, Natal, v. 2, n. 34, p. 259-275, 2018.

LÜCK, Heloísa. Liderança em gestão escolar. 9. ed. Petrópolis: Vozes, 2014.

MACHADO, Vivian de Andrade Torres. A atuação do coordenador pedagógico na formação de professores das escolas municipais de Educação Infantil (E. M. E. I.s) de São Paulo. 154 f. 2015. Dissertação (Pós-Graduação em Educação) - Pontifícia Universidade Católica de São Paulo, São Paulo, 2015.

MAHONEY, Abigail Alvarenga;ALMEIDA, Laurinda Ramalho de. Afetividade e processo ensino-aprendizagem: contribuições de Henri Wallon. Psicologia da Educação, São Paulo, n. 20, p. 11-30, jan. 2005.

MATSUDA, Adelina Braga. A formação contínua docente na rede pública estadual paulista:as relações entre o professor coordenador do núcleo pedagógico, o professor coordenador e o professor. 104 f. 2018. Dissertação (Pós-Graduação em Educação) Universidade Federal de São Paulo, Guarulhos, 2018.

MELO, Silvana Faria de. Vivências do coordenador pedagógico iniciante no contexto escolar: sentidos e significados mediando a constituição de uma identidade profissional. 188 f. 2015. Dissertação (Pós-Graduação em Desenvolvimento Humano) - Universidade de Taubaté, Taubaté, 2015.

MIZIARA, Leni Aparecida Souto; RIBEIRO, Ricardo; BEZERRA, Giovani Ferreira. O que revelam as pesquisas sobre a atuação do coordenador pedagógico. Revista Brasileira de Estudos Pedagógicos, Brasília, v. 95, n. 241, p. 609-635, dez. 2014.

MONTEIRO, Leonardo Felipe Paes. A formação continuada do coordenador pedagógico e o trabalho de formação junto aos professores especialistas. 88 f. 2018. Dissertação (PósGraduação em Educação) - Universidade Estadual Paulista, Sorocaba, 2018.

MORAES, Roque; GALIAZZI, Maria do Carmo. Análise Textual Discursiva. 3. ed. Ijuí: Unijuí, 2020.

MOSQUINI, Juliane do Nascimento. A mediação do coordenador pedagógico no desenvolvimento profissional de professores que ensinam Matemática. 277 f. 2019. Tese (Pós-Graduação em Educação) - Universidade Estadual Paulista, Presidente Prudente, 2019.

NÓVOA, António. Formação de professores e profissão docente. In: NÓVOA, António (org.). Os professores e a sua formação. 2. ed. Lisboa: Nova Enciclopédia, 1995. p. 15-33.

NÓVOA, António. Firmar a posição como professor, afirmar a profissão docente. Cadernos de Pesquisa, São Paulo, v. 47, n. 166, p. 1106-1133, out. 2017.

OLIVEIRA, Carolina Alves de. O (a) professor(a) coordenador(a) pedagógico(a) na formação em serviço dos (as) docentes do Ensino Fundamental II: uma análise dessa 
função em uma rede municipal de ensino do interior paulista. 124 f. 2018 . Dissertação (PósGraduação em Educação) - Universidade Federal de São Carlos, São Carlos, 2018.

OLIVEIRA, Elisangela Carmo de. O coordenador pedagógico como agente de mudanças na prática docente. 150 f. 2015. Dissertação (Pós-Graduação em Educação) - Pontifícia Universidade Católica de São Paulo, 2015.

ORFÃO, Elizabeth Tagliatella. O papel do coordenador pedagógico na formação crítica de professores: contribuições e desafios. 115 f. 2018. Dissertação (Pós-Graduação em Educação) - Pontifícia Universidade Católica de São Paulo, São Paulo, 2018.

PALLIARES, Neli Regina. Sou CP na Educação Infantil, e agora? Um estudo sobre o papel do coordenador pedagógico como formador de professores. 135 f. 2010. Dissertação (Pós-Graduação em Educação) - Universidade Metodista de São Paulo, São Bernardo do Campo, 2010.

PERINI, Renata Livia Soares. O coordenador pedagógico e a formação de professores alfabetizadores no município de São Paulo. 296 f. 2018. Dissertação (Pós-Graduação em Educação) - Universidade de São Paulo, São Paulo, 2018.

PIMENTA, Selma Garrido. Professor reflexivo: construindo uma crítica. In: PIMENTA, Selma Garrido; GHEDIN, Evandro (org.). Professor reflexivo no Brasil: gênese e crítica de um conceito. 7. ed. São Paulo: Cortez, 2012. p. 20-62.

QUEIROZ, Lindinalva Ferreira de. Escuta de professores e professoras sobre os sentidos da atuação do coordenador pedagógico na formação continuada centrada na escola. 146 f. 2018. Dissertação (Pós-Graduação em Educação Contemporânea) - Universidade Federal de Pernambuco, Caruaru, 2018.

RODRIGUES, Kátia Martins. O potencial de um grupo colaborativo para a constituição do professor coordenador como formador de docentes. 171 f. 2017. Dissertação (PósGraduação em Educação) - Pontifícia Universidade Católica de São Paulo, São Paulo, 2017.

RUDNICK, Marilda da Silva. A coordenação pedagógica e a práxis educativa na escola. 111 f. 2014.Dissertação (Pós-Graduação em Educação) - Universidade Federal de Mato Grosso, Rondonópolis, 2014.

SAMPAIO, Mariana Muniz. O coordenador pedagógico e a formação continuada de professores em serviço: uma análise em escolas públicas da região metropolitana do estado de Sergipe. Dissertação (Pós-Graduação em Educação) - Universidade Federal de Sergipe, São Cristóvão, 2018.

SANTOS, Vania Ida Malavasi dos. Os desafios do professor coordenador pedagógico na formação continuada dos docentes do ensino fundamental: o caso da região do Vale Do Ribeira/SP. 140 f. 2012. Dissertação (Pós-Graduação em Educação) - Universidade Metodista de São Paulo, São Bernardo do Campo, 2012.

SAVIANI, Dermeval. A supervisão educacional em perspectiva histórica: da função à profissão pela mediação da ideia. In: FERREIRA, Neura SyriaCarapeto (org.). Supervisão educacional para uma escola de qualidade. 3. ed. São Paulo: Cortez, 2002. p. 13-38. 
SCHÖN, Donald. Formar professores como profissionais reflexivos. In: NÓVOA, António (org.). Os professores e a sua formação. 2. ed. Lisboa: Publicações Dom Quixote, 1995. p. 77-91.

SENTOMA, Thays Roberta de Abreu Gonzaga. O fazer de formador e de acompanhamento pedagógico do coordenador pedagógico. 136 f. 2020 . Dissertação (PósGraduação em Educação) - Pontifícia Universidade Católica de São Paulo, São Paulo, 2020.

SHIGUNOV NETO, Alexandre; FORTUNATO, Ivan. Donald Schön e o "professor reflexivo". In: SHIGUNOV NETO, Alexandre; FORTUNATO, Ivan (org.). 20 anos sem Donald Schön: o que aconteceu com o professor reflexivo? São Paulo: Hipóteses, 2017. p. 512.

SILVA, Adalberto. O papel do coordenador pedagógico na formação dos professores. 127 f. 2012. Dissertação (Pós-Graduação em Educação) - Universidade Metodista de São Paulo, São Bernardo do Campo, 2012.

SIMÃO, Dimas Cássio. O impacto da formação continuada de professores nas escolas com bom desempenho em matemática: o caso da rede escolar SESI-SP. 104 f. 2012. Dissertação (Pós-Graduação em Educação) - Pontifícia Universidade Católica De São Paulo, São Paulo, 2012.

TAMASSIA, Silvana Aparecida Santana. Ação da coordenação pedagógica e a formação continuada dos professores do ensino fundamental I: desafios e possibilidades. $285 \mathrm{f}$. 2011. Dissertação (Pós-Graduação em Educação) - Pontifícia Universidade Católica De São Paulo, São Paulo, 2011.

TARDIF, Maurice. Saberes docentes e formação profissional. 3. ed. Petrópolis: Vozes, 2002.

TAVANO, Vinicius. Formação em serviço de professores em escolas municipais do extremo leste da capital paulista. 218 f. 2013. Dissertação (Pós-Graduação em Educação, Arte e História) - Universidade Presbiteriana Mackenzie, São Paulo, 2013.

VIEIRA, Cleomar Maciel de Araújo. O Coordenador Escolar e a Formação Continuada de Professores nas Escolas de Ensino Médio da CREDE Jaguaribe-CE: limites e potencialidades. 174 f. 2019. Dissertação (Pós-Graduação Profissional em Gestão e Avaliação da Educação Pública) - Universidade Federal de Juiz de Fora, Juiz de Fora, 2019.

VIGOTSKI, Lev Semenovitch. Pensamento e linguagem. 4. ed. São Paulo: Martins Fontes, 2008.

VOLPE, Tatiana Alves Lara. O coordenador pedagógico e as relações afetivas promotoras de desenvolvimento. 127 f. 2019. Dissertação (Pós-Graduação em Educação) -Pontifícia Universidade Católica de São Paulo, São Paulo, 2019.

XAVIER, Jusimara. A formação continuada docente no espaço/tempo da coordenação pedagógica. 168 f. 2015.Dissertação (Pós-Graduação em Educação) - Universidade de Brasília, Brasília, 2015.

ZUMPANO, Viviani Aparecida Amabile. O coordenador pedagógico e o seu papel na formação continuada em serviço do professor de educação infantil (creche). 194 f. 2010. 
Revista de Educação, Ciência e Tecnologia

Dissertação (Pós-Graduação em Educação) - Pontifícia Universidade Católica de São Paulo, São Paulo, 2010.

Recebido em março de 2021.

Aprovado em maio de 2021. 